\title{
Los epígrafes delatores ${ }^{\circ}$
}

\author{
Enrique Butti $\bullet$ \\ Escritor - periodista \\ Fabricio Welschen $\cdots$ \\ Universidad Nacional del Litoral
}

\section{Resumen}

En el presente artículo se indagará en la operatividad y los alcances que tienen los epígrafes en algunos de los cuentos del escritor estadounidense Edgar Allan Poe. De este modo, se focalizará en aquellos cuentos en los que los epígrafes operan en función de anticipar el desenlace de la trama así como también en aquellos otros en los que estos paratextos direccionalizan la lectura hacia una determinada interpretación

\section{Palabras clave}

- Epígrafes · Edgar Allan Poe · Literatura

\begin{abstract}
This article configures an investigation on the extent and effects of the epigraphs in some of Edgar Allan Poe's tales. Thus, it will focus on how the epigraphs operate in order to anticipate the conclusion of a given storyline and how these paratexts encompass a particular interpretation.
\end{abstract}

\section{Key words}

- Epigraphs · Edgar Allan Poe · Literature

\footnotetext{
- Una primera versión sucinta de este trabajo, fue publicada en el diario El Litoral de Santa Fe, el 23 de octubre de 2014

- Escritor. Autor entre otros títulos de Indí (1998), La daga latente (2006), El novio (2007) y El centro de la gravedad (2012).

-.. Licenciado en Letras por la Universidad Nacional del Litoral.
} 
Epígrafe es una cita que, a modo de sentencia, introduce, resume o direcciona la lectura del texto al cual encabeza. En nuestro tiempo ha comenzado vigorosamente a ejercer una función menos decorosa: la de una invocación elegida no por su pertinencia sino por la firma, es decir, para conquistar prestigio bajo el manto de un nombre consagrado («si escribo algo con afán comercial y lo escudo con la auspiciosa rúbrica de un autor canónico, atenúo el carácter bastardo de mi texto») o para establecerse en una filiación determinada («si cito a un autor de culto yo paso a formar parte de ese culto»). De esta inocua perversión forma parte también la imposición de acompañar los trabajos académicos con epígrafes que sirvan de inmediato, antes de leer siquiera una frase del trabajo, para, otra vez, embanderar filiaciones o conferir prestigio.

Los cuentos de Edgar Allan Poe son de variada especie. Se lo considera iniciador de distintos géneros y categorías de narraciones: fundador del género policial (detectivesco), preceptor del cuento de horror (en una amplia gama que él rotuló con términos que hoy nos resultan ambiguos: Cuentos de lo grotesco y arabesco); precursor del relato fantascientífico (con «Hans Pfaal», por ejemplo); adelantado en la tematización de lo urbano («El hombre de las muchedumbres») y, lo menos reconocido hasta hoy, cultor de ese tipo de narración de índole metaliteraria que haría eclosión precisamente en nuestro tiempo, y que podríamos definir como "narrativa ensayística», con producciones que incluirían a cuentos como «Pierre Menard, autor del Quijote», de Jorge Luis Borges, a algunas novelas de Vladimir Nabokov y de Milan Kundera, por no citar a tantos emuladores que llevaron este tipo de literatura a la mera repetición y a una secuela de tics honrada por la academia catedrática, tan presente en la narrativa actual argentina (Ricardo Piglia y compañía). Los cuentos de Poe que se inscriben en esta línea ("Jamás apuestes la cabeza al diablo", "Cómo escribir un artículo de Blackwood» y tantos otros) se encuentran signados por una impronta paródica, cuyo principal blanco es la literatura de los trascendentalistas y la ampulosa jerga de los escritores de la Nueva Inglaterra de aquel tiempo.

Consecuente a esta variedad en sus cuentos, Poe selecciona y utiliza de diversas maneras epígrafes en muchos de sus textos. Usa dichos populares, en los que bromea instituyendo como eminente, por ejemplo, a una pregunta banal y atemporal como "¿Qué hora es?», que adscribe a un «Dicho antiguo» en el cuento «El diablo en el campanario». Usa citas en su lengua original (varias en griego y latín, en francés, en alemán y en italiano). Usa un epígrafe que debía serle tan caro que siete años más tarde lo retoma como título de un cuento («Mellonta Tauta»), o el de «El cuento mil dos de Scheherezade», que un año antes había glosado en «Un relato de las montañas escabrosas» (esa sentencia clave en Poe que reza: «La verdad es más extraña 
que la ficción»). Usa epígrafes que recurren en el final del mismo cuento, en una estructura circular que, en el caso de «El hombre de las muchedumbres» alcanza no sólo a la repetición del epígrafe (que por otro lado ya aparecía dentro del primer cuento publicado de Poe, en 1832) sino también a la cita que abre y cierra el cuento.

Los casos más representativos son los epígrafes que anticipan el desenlace de la historia, como en dos de los cuentos más célebres del autor. «William Wilson» es la historia de un Doppelgänger, de un doble. William Wilson padece la constante presencia de un tocayo que lo sigue desde su época de estudiante e interfiere cada vez que comete una mala acción. No es necesario llegar al final, cuando el narrador mata a puñaladas a su doble, para entender lo que anticipa el epígrafe: «¿Qué decís de ello? ¿Qué decís de la torva conciencia, ese espectro en mi camino? (Pharronida de Chamberlayne)».

En cuanto al de «El escarabajo de oro» resulta curioso: «iQué hay! ¡Qué hay! ¡Este tipo baila como un loco! Lo ha picado la Tarántula (Todo equivocado)». Rolando Costa Picazo recurre a Burton Pollin para sugerir que el epígrafe fue inventado por Poe. Entonces, el «Todo equivocado» no es una referencia bibliográfica, sino que señala que el contenido del epígrafe es una equivocación: el sujeto, más allá de si ha sido picado por una tarántula, no está loco. ¿Qué relación tiene esto con el cuento? Precisamente, el comportamiento del protagonista, William Legrand, considerado loco, responde en realidad a un procedimiento estrictamente metodológico, cuyo fin es descifrar el enigma que le permite acceder a un tesoro.

En el caso «Ligeia», el cuento favorito de Poe, la incidencia del epígrafe cobra una mayor importancia:

Y allí yace la voluntad que no muere. ¿Quién conoce los misterios de la voluntad, con su vigor? Pues Dios es sólo una gran voluntad que invade todas las cosas gracias a su intensidad. El hombre no se entrega a los ángeles, ni tampoco por completo a la muerte, salvo sólo por causa de la debilidad de su endeble voluntad (Joseph Glanvill).

No se ha localizado este pasaje en los escritos de tal autor, repitiéndose lo que no es raro en los epígrafes de Poe, que rozan lo apócrifo. A diferencia de los casos anteriores, el epígrafe en "Ligeia» no sólo anticipa el final sino que también impone una exégesis. Queda la duda de si lo acontecido en la historia es un suceso sobrenatural o si todo es producto del delirio de un narrador que además de evidenciar señales de locura es también muy afecto al consumo de opio. Pero si uno se remite al epígrafe, éste ya no deja margen alguno para la ambigüedad: su empleo en el cuento de Poe direccionaliza la lectura hacia una interpretación sobrenatural de los hechos.

El epígrafe a «El misterio de Marie Rogêt» interesa por dos razones: una, estratégica, y otra, llamémosle así, de reverberación metafísica. Pertenece a Novalis y reza:

Existen series ideales de sucesos que corren paralelamente a los reales. Raras veces coinciden entre sí. En general, los hombres y las circunstancias modifican la sucesión ideal de los acontecimientos, de tal manera que parece imperfecta, y sus consecuencias son igualmente imperfectas. Así, con la Reforma, en lugar del protestantismo, vino el luteranismo.

El cuento (al que Poe llama «artículo») se publicó en 1842, cuando seguía causando conmoción y seguía sin resolverse el caso del asesinato en Nueva York de 
una muchacha llamada Mary Cecilia Rogers. Poe aprovecha para escribir sobre el misterioso asesinato de una grisette parisina llamada Marie Rogêt en circunstancias similares al de la neoyorquina. Similares, no idénticas, ya que para adecuar las conclusiones de Dupin, Poe necesitó cambiar algunos hechos. De ahí pues que, precisamente debido al anzuelo de presentar en el título un nombre ficticio que se identificaba con el de la víctima real, Poe tuviera la necesidad de advertir desde el inicio que el caso que relataba mantenía apenas coincidencias con el de Mary Cecilia Rogers, y que la resolución (dénoument) del misterio de Marie Rogêt no implicaba sugerir métodos de investigación ni conclusiones del mismo tenor para el crimen de la otra Mary. El epígrafe de Novalis acerca de que las «series ideales» y los sucesos paralelos raramente coinciden tiene ese puntual motivo de descargo. Posteriormente, cuando volvió a publicar el cuento en 1845, agregó un texto apócrifo, atribuido a los editores, donde explicita que no hay que relacionar «los misterios de Marie Rogêt» con los de Mary Cecilia Rogers. Y hay una segunda razón para ese epígrafe de Novalis: las resonancias filosóficas e históricas (la inclusión de la frase final sobre la Reforma, el protestantismo y el luteranismo), una suerte de amplificación de las tesis que Dupin propondrá en el cuento, sobre todo la de «descartar los puntos interiores de la tragedia y concentrar la atención en lo que la rodea», ya que "la experiencia demuestra — y una filosofía verdadera también — que una vasta parte de la verdad, quizás la mayor parte, surge de lo que parece carecer de importancia», de esas mínimas diferencias con respecto a las "series ideales» que modifican sin embargo sustancialmente la realidad, como argumenta Novalis.

No es casual que los últimos cuentos de Poe carezcan de epígrafes. La escritura arrebatada de estos cuentos revela una urgencia que olvida cualquier arbitrio o referencia. La narrativa ensayística que recurre en esos últimos cuentos se torna feroz, arremetiendo contra todos, contra la naturaleza imperfecta, el Populacho, el Progreso, la Tecnología, la República, los tipógrafos, los Artistas Artificiales —amén de los usuales blancos, los trascendentalistas y los intelectuales en boga de la Nueva Inglaterra. Llama Cant («jerigonza») a Kant, Neuclides a Euclides, Hog («cerdo») a Francis Bacon ("panceta»). Escribe un cuento («Hop-Frog») para vengarse de todos los enemigos que lo acorralan (y cuyos chismes truncan su compromiso matrimonial con Sarah Whitman).

Sólo el arte se presenta como capaz de rescatarnos del magma defectuoso que es la realidad y devolvernos el Paraíso Perdido, esa "pieza de composición, en la cual ni el gusto crítico más exigente habría sugerido una enmienda». El artista que es Poe en sus últimos cuentos ya lucha solo, sin otra voz que sea digna de acompañarlo para estamparse en la primera línea de sus escritos.

En su último cuento, que queda inconcluso, un hombre totalmente aislado en un faro, en medio del mar, descubre "lo triste que suena la palabra 'solo'» y el eco aciago que provocan las paredes cilíndricas de la torre. Éstas son las últimas palabras con que se interrumpe el cuento:

... cuando sopla un viento de sudoeste, el mar puede alcanzar una mayor altura que en cualquier otra parte del mundo, con la única excepción del Estrecho de Magallanes. Ningún mar, no obstante, podría lograr hacerle daño a esta sólida pared con remaches de hierro que, a cincuenta pies de la marca de pleamar, es de cuatro pies de espesor, cuando menos... La base sobre la cual descansa la estructura me parece que es de creta... («...The basis on which the structure rests seems to me to be chalk...») 
Quizás sean las últimas palabras que Poe escribe: la imagen de una torre de acero sobre una base endeble.

\section{Referencia bibliográfica}

Poe, E.A. (2010). Cuentos completos. [Traducción, notas e introducción de Rolando Costa Picazo]. Buenos Aires: Colihue. Vol. I y II. 